In the Public Eye

\title{
On earth as it is in hell
}

\section{Hollywood's view of paramedics at work}

Two recent movies, Broken Vessels (A-Pix Entertainment) and Bringing Out the Dead (Touchstone), portray the lives of those who work for the emergency medical services in urban America. Or at least they claim to.

Broken Vessels tells the story of Tom (Jason London), an emergency medical technician who arrives in Los Angeles while trying to escape his past in Altoona, Pennsylvania. He lands a job as an ambulance driver and is teamed up with Jimmy (Todd Field), a senior Los Angeles paramedic whose best skill seems to be snatching his sunglasses off his face and trying to look cool.

Within 10 minutes of the start of the movie, the 2 paramedics are drinking alcohol, picking up women, having sex, buying heroin on the street corner, and getting high - all while on duty, mostly in the ambulance. They then start stealing from their patients to support their drug habits and eventually run afoul of a drug dealer, who in turn tries to shoot them. As they speed away in the ambulance, they crash quite spectacularly. Jimmy is killed, and Tom decides he has to become more responsible.

Bringing Out the Dead tells the story of Frank Pierce (Nicolas Cage), a paramedic in New York City who is haunted by the ghost of a young girl named Rose whom he was 


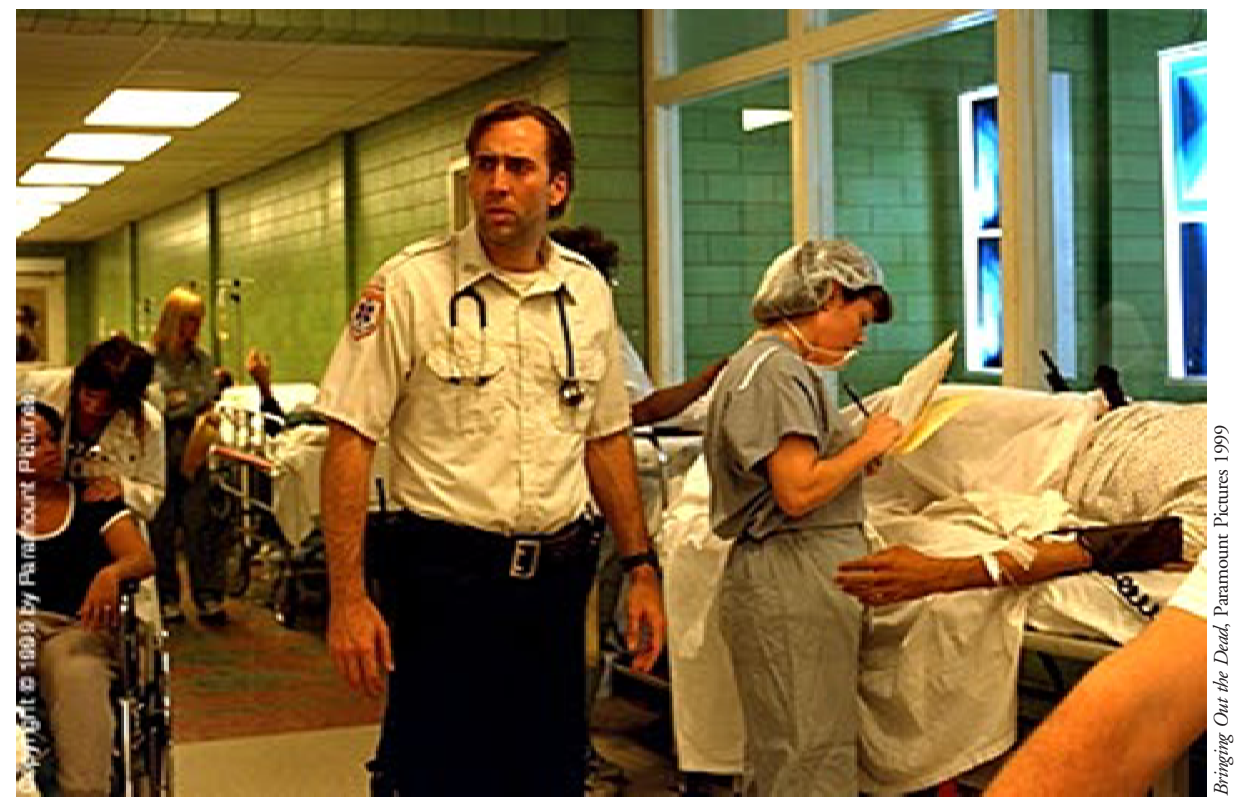

unable to resuscitate following an acute asthmatic attack. He sees her face on nearly every woman he encounters, and he is certain that all he needs is to save one person's life to move beyond the memory.

When Frank resuscitates the elderly $\mathrm{Mr}$ Burke (Cullen O Johnson), he falls for Burke's daughter Mary (Patricia Arquette). Unfortunately, Burke's recovery is minimal; he is kept alive only by life support and becomes an additional burden to Frank. There is hope for absolution when Frank and his partner Marcus (Ving Rhames) deliver twins from a woman, while her boyfriend stands by and swears that they are both virgins. But one of the babies dies, and so Frank's haunting continues. Ultimately, he overcomes the ghosts by disconnecting Mr Burke from his ventilator and allowing him to die peacefully.
Broken Vessels is a movie about partying, drinking, and drug taking, and the main characters just happen to be paramedics. That the movie is set primarily in an ambulance adds nothing to the story line, but it does allow amazing cinematography involving flashing red and white lights and blurred images. The film focuses on drug addiction, rather than the life and role of paramedics, so it likely will not have much effect on the public's perception of these professionals.

Martin Scorcese, director of Bringing Out the Dead, also uses striking images, casting a glowing aura around Cage's character. In contrast to Broken Vessels, however, Frank Pierce's job as a paramedic is central to the film's plot. Indeed, through the first half of the movie, we get to know him as a compas- sionate and competent provider of emergency medical care.

It is, therefore, more disappointing when he and Marcus have a drink in the ambulance to celebrate the "virgin birth," when he follows Mary to a drug den and indulges in its offerings, and when he and another paramedic go hunting for someone to beat up in order to vent their frustrations. Unfortunately, the audience is likely to accept Cage's portrayal of a paramedic, and to extend their perceptions of his character to the profession as a whole.

Both of these movies have glimmers of reality, mostly in their depiction of the emergency scenes and the interactions between paramedics, law enforcers, firefighters, and bystanders. They also go some way in portraying the frustrations of the work schedule and the divergent segments of society encountered by ambulance crews. Even some of the more despicable traits of the paramedics might not be that far fetched. But the difference between true life and these movies is that in reality - for the most part-no single call, no single shift, no single patient, and no single paramedic manifests all of these characteristics. Not even in Los Angeles or New York City.

These films are almost saved by their moments of humor. But they do not accurately describe the life a paramedic in big-city America. Urban legends - or perhaps urban myths — make for better stories. The real lives of us paramedics can be, in contrast, rather mundane.

\section{Lawrence Brown}

Syracuse, New York

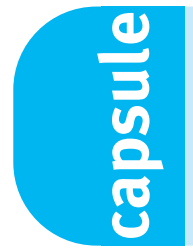

Cartoons contain violence wjm editors love feature-length cartoons and we are grateful to JAMA (2000;238:2716-20) for printing a comprehensive list of all those released since 1937. A content analysis describes all the films as violent to a greater or lesser extent, and parents wanting to limit their children's exposure should stick to Winne the Pooh and Dumbo, which contain only 1 minute of violence each. The classic A Bug's Life is the second most violent animated film ever released. No doubt grasshoppers account for most of it.

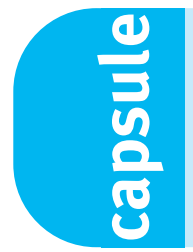

History repeats itself A historical medical textbook, written by an English monk over 800 years ago, has gone on display at the US National Library of Medicine in Bethesda, MD after an absence of over half a century. The book, which contains many of Hippocrates' famous aphorisms, disappeared under suspicious circumstances sometime in the 1940 s. It turned up last year at a rare book market in Southern California. The dealer donated the book to the library after some "decorous wrangling." 